\title{
Supporting Digital Humanities for Knowledge Acquisition in Modern Libraries
}

Kathleen L. Sacco

State University of New York at Fredonia, USA

Scott S. Richmond

State University of New York at Fredonia, USA

Sara Parme

State University of New York at Fredonia, USA

Kerrie Fergen Wilkes

State University of New York at Fredonia, USA

A volume in the Advances in Library and Information Science (ALIS) Book Series

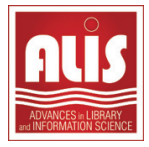

Information Science
REFERENCE

An Imprint of IGI Global 
Managing Director:

Managing Editor:

Director of Intellectual Property \& Contracts:

Acquisitions Editor:

Production Editor:

Development Editor:

Typesetter:

Cover Design:
Lindsay Johnston

Austin DeMarco

Jan Travers

Kayla Wolfe

Christina Henning

Brandon Carbaugh

Lisandro Gonzalez \& Michael Brehm

Jason Mull

Published in the United States of America by Information Science Reference (an imprint of IGI Global)

701 E. Chocolate Avenue

Hershey PA, USA 17033

Tel: 717-533-8845

Fax: 717-533-8661

E-mail: cust@igi-global.com

Web site: http://www.igi-global.com

Copyright ( $) 2015$ by IGI Global. All rights reserved. No part of this publication may be reproduced, stored or distributed in any form or by any means, electronic or mechanical, including photocopying, without written permission from the publisher. Product or company names used in this set are for identification purposes only. Inclusion of the names of the products or companies does not indicate a claim of ownership by IGI Global of the trademark or registered trademark.

Library of Congress Cataloging-in-Publication Data

Supporting digital humanities for knowledge acquisition in modern libraries / Kathleen L. Sacco, Scott S. Richmond, Sara Parme, and Kerrie Fergen Wilkes, editors.

pages $\mathrm{cm}$

Includes bibliographical references and index.

ISBN 978-1-4666-8444-7 (hardcover) -- ISBN 978-1-4666-8445-4 (ebook) 1. Humanities--Digital libraries. 2. Humanities--Electronic information resources. 3. Humanities--Research--Data processing. 4. Humanities--Study and teaching (Higher) I. Sacco, Kathleen L., 1970- editor. II. Richmond, Scott S., 1982- editor. III. Parme, Sara M., 1985- editor. IV. Wilkes, Kerrie Fergen, editor.

AZ195.S86 2015

025.06'0013--dc23

2015009642

This book is published in the IGI Global book series Advances in Library and Information Science (ALIS) (ISSN: 23264136; eISSN: 2326-4144)

British Cataloguing in Publication Data

A Cataloguing in Publication record for this book is available from the British Library.

All work contributed to this book is new, previously-unpublished material. The views expressed in this book are those of the authors, but not necessarily of the publisher.

For electronic access to this publication, please contact: eresources@igi-global.com. 


\title{
Chapter 12 \\ From Digital Arts and Humanities to DASH
}

\author{
Justin Schell \\ University of Minnesota Libraries, USA \\ Jennie M. Burroughs \\ University of Minnesota Libraries, USA
}

\author{
Deborah Boudewyns \\ University of Minnesota Libraries, USA \\ Cecily Marcus \\ University of Minnesota Libraries, USA
}

Scott Spicer
University of Minnesota Libraries, USA

\begin{abstract}
Academic libraries around the United States have been responding to an emerging style of research, the digital humanities, that promises to expand and revolutionize the humanities. Libraries are finding themselves to be generative sites of innovative partnerships and projects. Seeing a new opportunity to showcase cutting edge research and demonstrate value in an era of competitive demands for financial resources, there is significant incentive for libraries to quickly anticipate scholarly needs. Yet how do academic libraries best support a field of practice that is still developing? To address these issues, the University of Minnesota Libraries conducted a multi-year assessment of scholarly trends and practices, infrastructure needs, and roles of digital humanities centers and academic libraries, the University of Minnesota Libraries have designed and are in the process of implementing a service model as part of its Digital Arts Sciences + Humanities (DASH) program.
\end{abstract}

\section{INTRODUCTION}

The emergence of digital humanities scholarship offers libraries an opportunity to develop improved systems of support and to engage with long-standing questions of librarianship in new ways. This chapter focuses on how the University of Minnesota (UMN) Libraries have addressed the needs of digital humanities scholars and initiatives in the midst of an uncertain and rapidly changing field, by developing an informed, strategic response and service model that can function at scale. The title of the chapter, "From Digital Arts and Humanities to DASH", represents the two main phases of the program development to date. The first section provides an overview of how, beginning in 2011, the UMN Libraries initially ap-

DOI: $10.4018 / 978-1-4666-8444-7 . c h 012$ 
proached supporting digital arts and humanities by surveying its practitioners and existing infrastructure, identifying research challenges and service gaps in the context of a large research university. This section presents findings from a series of interviews with faculty and staff and from a scan of local infrastructure and support mechanisms. The second section of the chapter discusses the Libraries' response to this investigative work: the 2013-present design and implementation of a comprehensive service model that addresses the needs of campus and regional scholarly communities engaging in "Digital Arts Sciences + Humanities", or "DASH". The section also describes the importance of embracing an iterative and experimental approach to services and some mechanisms for addressing critical sustainability issues in a pilot period.

Though the discussion focuses specifically on the UMN Libraries context, readers from many different institutions will see their own experience reflected in the environmental scans, the hiring of specific staff, and the pilot approach to providing support for emerging modes of research and pedagogy.

\section{INVESTIGATING DIGITAL ARTS AND HUMANITIES}

\section{Scholarly Perspectives}

Beginning in 2011, the University of Minnesota Libraries sponsored the formation of a digital arts and humanities working group in order to investigate and recommend a coherent strategy for library support of emerging digital arts and humanities scholarship on a large, distributed campus. The group included representatives from a range of related areas at the university: library departments (e.g., Arts and Humanities, Digital Library Services, Archives and Special Collections), the Office of Information Technology (OIT), and the College of Liberal Arts Office of Information Technology (CLA-OIT). The explicit inclusion of "art" in the working group's title reflected recognition that digital art and data arts are growing practices that may not always be represented adequately in discussions of the digital humanities. Within this local context, there was already evidence of burgeoning interest in digital arts and humanities across disciplines that included students and faculty in departments such as Art, Art History, Computer Science, Cultural Studies \& Comparative Literature, English, Geography, History, Theatre Arts and Dance, and Writing Studies.

The two years of the group's work from spring 2011 to spring 2013 was both exploratory and analytical with a focus on: assembling representative case studies of digital humanities centers and institutes (including a survey of digital humanities support models, degree programs, certificates, tool kits, etc.); assessing local digital humanities initiatives and interest through interviews and online surveys with faculty and key staff; and identifying current tools and resources for digital humanities work locally and externally. The objectives of this foundational research were to gain a more complete understanding of the local community and its relationship to national conversations and issues; to identify the major obstacles and challenges that scholars and practitioners often face; and to make recommendations based on our expertise for how the University of Minnesota Libraries would continue to respond to the needs of digital scholars in a forward-looking manner. 


\section{External Perspectives: Literature, Consultants, Institutions, and Programs}

The initial work conducted by the Digital Arts and Humanities (DAH) Working Group involved gathering information about the digital humanities. Consulted resources reflected basic questions about how academics define digital humanities and the impact of the digital humanities on research, teaching, and learning. Information on infrastructure was sought to learn how digital humanities activities and projects were being facilitated on college campuses and what support mechanisms were being used to transform research and teaching practices. At the time, the group was interested in knowing the major players, institutions and individuals, prominent collaborations, key tools, best practices, and any discussions on the time/resources needed for the creation and support of DAH.

Robert Allen articulated a description of digital humanities (DH) in announcing Digital Innovation Lab at the University of North Carolina that resonated with the working group:

Digital humanities is not just about individual scholars using computers in their research. It represents a potentially transformative change across all the ways we work as academics: from the questions we ask, to the kinds of people we work with; from the ways we communicate knowledge to our peers and our students, to the ways we relate to the world beyond the University. (Lach, 2012, para. 6)

In articulating the ways this definition plays out amongst the emerging field of digital humanities, we read a number of written publications as well as looked at a variety of digital humanities and digital scholarship centers around the world.

Theoretical readings reviewed early on assisted in grounding a holistic understanding about the digital humanities. The working group drew on the guiding definitions and principles articulated by Fitzpatrick (2011) in her Chronicles of Higher Education piece, "The Humanities, Done Digitally". Similarly, the writings of Alvarado (2011) and Liu (2012) helped to inform the working group's early conceptions of digital humanities. The DAH group drew on A Survey of Digital Humanities Centers in the United States (Zorich 2008) as it planned a study of the digital humanities initiatives of thirty-two institutions; this working group looked at projects, websites, and mission statements for best practices. Indicating the timeliness of the work, the Association of Research Libraries published Spec Kit 326: Digital Humanities around the time the working group completed this review, and the SPEC Kit's comprehensive work mirrored the working group's findings.

Non-traditional online platforms offered models for community infrastructure around digital humanities. One exemplary platform included the work of Rhizome (http://rhizome.org/) with their mission to "expand communities of practices" for artists. Observing the formation of the Hathi Trust Research Center (http://www.hathitrust.org/htrc) and ProjectBamboo (http://www.projectbamboo.org/) stimulated thinking about functional frameworks for administrating and managing DAH content. In a related vein, multimodal publishing platforms form a key element to digital humanities scholarship, and the DAH group looked to work generated by Tara McPherson and the University of Southern California, such as the journal Vectors and the web authoring tool Scalar, for insight and use cases.

For some on-site conversations, the working group invited two guest speakers. The University of Illinois English and Digital Humanities Librarian, Harriett Green, spoke to the working group and an invited audience about the development of the Illinois digital humanities program. Professor of History, Dan Cohen, then head of the Roy Rosenzweig Center for History and New Media at George Mason University, was invited to share his insights on digital humanities tools and projects (D. Cohen, personal 
communication, April 20,2012). In particular, Cohen's comment in his talk that libraries serve as "neutral ground" on campus resonated strongly with the working group and was a foundation for the "library as hub" concept, which will be discussed more fully later in the chapter.

\section{Scholarly Perspectives from the Homefront}

To better understand the local environment, the working group conducted a series of interviews in 2012 with arts and humanities faculty and select staff, followed later by a brief survey sent to the campus digital humanities listserv. Interview subjects were selected based on perceived or demonstrated interest in the field. Questions addressed whether or not the participant identified as a digital humanist, challenges of DAH work, sources of research support, data preservation practices, research audience, and support from home departments (see Appendix).

The scholars, publishers, and instructors who were interviewed and surveyed offered a range of responses to the question of whether or not they considered themselves a digital humanist, with some fully embracing the term and others expressing more wariness or even the definitive "No." An art history professor responded:

There are two ways to answer this. One is: what do you use, [e.g.] digital technologies? The other is: how do you think... in ways that digital culture makes possible? [I] am more concerned with the second. "Digital Culture" or the computer age happened because people's thought processes changed.

A university press staff member, squarely in the "Yes I am" group, was more interested in defining the digital arts and humanities as a field:

What is exciting about DH-there is too much information and too much data... it's impossible to synthesize-DH begins to get that-the kinds of knowledge we have, references we have makes us apply different tools to scholarly work. It's akin to the rise of theory in the 1970s. It changes what scholarship is, and it requires publishers to understand new methodologies and a new vocabulary.

Though some scholars embraced the concept of digital humanities and fully identified their work as part of the field, others shared a concern that the term "digital humanist" is polarizing, or even unimportant. Some scholars were finding their way organically through experimentation, opportunity, and curiosity, while others did not feel they had the technical skills or depth of experience needed to claim the title.

Regardless of their answers to the first question about whether they consider themselves digital humanities scholars, most interviewees conveyed an interest in creative and innovative research and research products that push the boundaries of process, technology, and scholarly inquiry, generally. Some articulated differences in perceptions of and engagement with technology itself, indicating that technology may be the means of scholarly inquiry, or it may be the subject of scholarly inquiry itself. The feedback from UMN scholars and staff demonstrated how the methodological and conceptual relationship of technology, research, and teaching/pedagogy was still in its nascent stages at the time.

The local scholars characterized their means of finding support as somewhat casual and haphazard: they tend to use support wherever they find it and with whomever they find (Figure 1). Technology support, in particular, is less about systematically seeking the best teacher or identifying the best resource than using whatever (or whomever) is most readily available at a given time, be it a student, departmental 
Figure 1. Digital humanities support interview responses

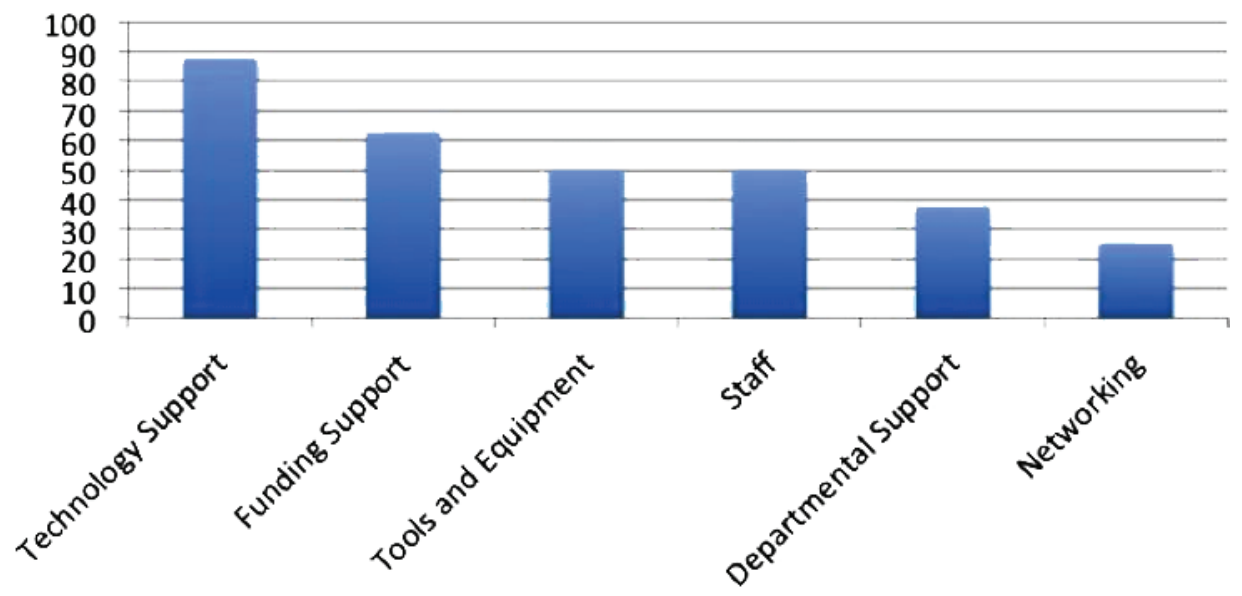

IT staff, or a friend at a different institution. As a result, solutions are often cobbled together, rarely iterative, and do not build a framework for problem-solving. Several interviewees noted how difficult it can be to find ample assistance in this work given the size of the institution and distributed nature of support at the University of Minnesota.

Many interviewees reported that a lack of infrastructure or knowledge about tools and development techniques (both how to use them or even that they exist) present obstacles to research. Legal concerns regarding copyright were also an issue of concern, and often, of confusion. A cultural studies faculty member discussed how legal interpretations by a university general counsel often get in the way of copyright liberties and fair use claims related to the Digital Millennium Copyright Act (DMCA). In addition, physical spaces on campus that integrate a wide variety of tools and equipment (global TV, gaming, etc.) are also often lacking and can be difficult to access on a large, fragmented campus.

Conceptually, the emerging and experimental nature of digital arts and humanities - with its expanding possibilities for source material, methods, and outcomes - can be overwhelming for some scholars. This sentiment was born out by our discussions with local scholars. Contrary to the interviewee who felt that the unending possibilities of digital scholarship are liberating and revolutionary, another lamented, "Research is an infinitude", and, faced with the ever-increasing number of digital tools, continued "When are you ever done?".

The nature and depth of challenges experienced by digital artists and humanists leads to the important question of support and service needs. In response to a survey question about support needs, survey participants requested help with technology. Funding, tool training, and staff support also ranked higher than the challenges of finding opportunities to network with colleagues. That said, participants noted ongoing difficulty in identifying campus technology partnerships along with making interdisciplinary connections. Furthermore, a major challenge discussed repeatedly by UMN scholars was a sense of their home departments' general disinterest in and lack of support for digital arts and humanities work. Marshaling the resources and the initiative to take on a new type of research, publishing, or teaching can be a lonely and less-than-gratifying experience day to day, or even worse, come time for promotion and tenure. 
Figure 2. Data storage interview responses

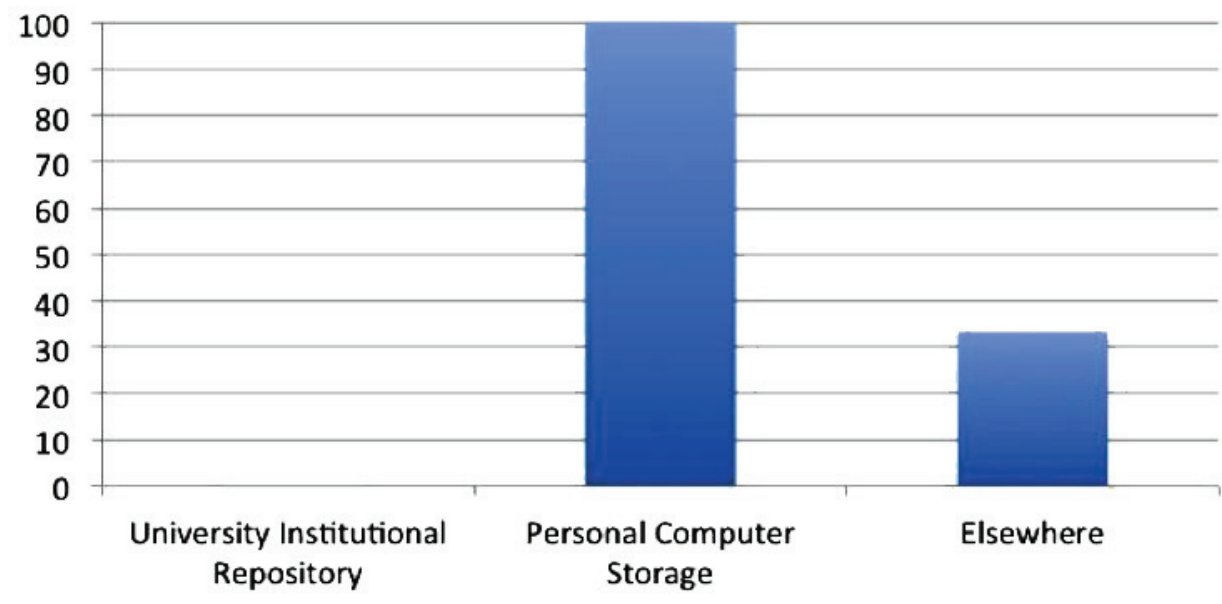

The increase of digital arts and humanities scholarship and student work inevitably raises the issue of data curation: What happens to the data and materials used and/or created in the course of a project or scholarly work? How is it preserved? Who will be able to access it in a year, 5 years, 50 years? We found that this important issue is often overlooked. "I don't really have a workflow", said one professor. "I would like to attend a workshop on that", she continued. The personal computer or filing system (hard drives, thumb drives, back up hard drives, emailing files to oneself, or even devising an email naming system to mimic one's personal computer naming/filing conventions) is often the extent of attention given to data management.

For many, the issue of long term, open access is overlooked entirely. Those who try to address data preservation and access find that they have neither the technical expertise nor the resources to do so adequately (and are often unaware of University-sponsored tools and services that can help them. Even the most advanced scholars consulted consider their personal computer to be a default solution for data storage (Figure 2).

\section{Campus Infrastructure and Service Gaps}

During the initial investigation period, the DAH group conducted a scan of relevant campus support services, experts, and other resources in order to determine existing service gaps on campus and in the Libraries. Because of the disaggregated nature of services at a large university, the task of uncovering and tracking all available services and support programs can be a challenge. However, the environmental scan effectively served as a way to identify a range and depth of expertise that could support DAH work, including digitization services, hosting/publishing platforms, media support services, textual/visual analysis services, GIS services, and data visualization/simulation spaces. Multiple campus units offer potential DAH services, which can collectively advance research, technology, curriculum design, and teaching.

As an example, the working group found a range of data services on campus, from department or college-specific to centralized to vendored. Some resources are free and well supported by trained staff (e.g., GIS training and equipment through U-Spatial, a coordinated campus GIS support program), while 
others are fee-based (e.g., digitizing physical books/manuscripts/photos, etc.). Some services offer a model that is purely do-it-yourself and others rely on vendors for service, such as converting obsolete analog video (e.g., Betamax, UMatic, etc.) to digital files.

In the area of preserving and disseminating work, the environmental scan also revealed that there are a number of established or in-development publication/hosting platforms available to students, faculty, and staff, and this continues to be an area of investment and exploration for the UMN Libraries. This includes platforms and services hosted by the Libraries (e.g., University Digital Conservancy, UMedia Archive) and the College of Liberal Arts (e.g., Digital Content Library, Media Mill).

As digital arts and humanities scholarship is more readily communicated through multimodal works, a range of disparate media support services are available from centralized media services provided by the Libraries (i.e., free production support for students projects and fee-based media digitization services). There are also several college-level media support services, such as media content conversion and delivery, and limited support for student video creation. Finally, several media support services are found at the department level, such as in the journalism, art, and music departments.

The environmental scan made it apparent that despite investment in supporting the digital needs of scholars, access to campus software, and support services for textual and visual analysis, in particular, are restricted or hidden. A number of campus-wide, college and department-based computation, visualization, and simulation services are, in fact, available and of value to digital humanities scholarship, but these are not often accessed by digital artists and humanists. One example is the Minnesota Supercomputing Institute within the College of Science and Engineering, which offers an array of services such as project consulting, computational servers, workstations, dedicated data storage, software program development, visualization tools and technical support. There are several variables that likely contribute to this perception of restriction, including a lack of general awareness about the specifics of each of these services and belief that these higher end services may not be available to artists and humanists, as they have traditionally been primarily accessed by scholars in other disciplinary areas.

Over the course of several months of focused conversations and assessment, it became clear that faculty members are seeking clearer paths to pursuing and sustaining digital arts and humanities work, even if they may not always name their work as such. There is a real desire to develop partnerships, particularly outside of one's primary discipline, and there is a need for institutional backing that will allow faculty to explore new areas while also progressing through the traditional promotion and tenure requirements. The DAH working group used this information to make recommendations for the role of the Libraries in the lifecycle of these pursuits positioning the Libraries to provide not only support, but also develop an environment that makes the Libraries a resource as well as a partner. The Libraries also focused on bringing together the disparate campus services associated with digital arts and humanities scholarship, serving as a leader and catalyst for new ideas and scholarship.

\section{FROM DAH TO DASH}

\section{Initial Actions/Early Steps}

Following the recommendations process, the DAH group began working in spring 2013 to address key service gaps and needs articulated by scholars that were identified above. This included organizing a Digital Arts and Humanities Networking Summit to bring together representatives and stakeholders from 


\section{From Digital Arts and Humanities to DASH}

potential and established service points supporting digital arts and humanities efforts. Summit participants spent an afternoon listening to presentations and collaborating in breakout sessions that considered issues, obstacles, roles, and sustainability related to digital arts and humanities research and services. The overarching topics that participants were asked to tackle in the breakout sessions included meeting the needs of the digital arts and humanities community through consultation and support; sustainable support and management of data and curated digital arts and humanities output; and determining levels of technology and functionality across campus services. Attendees drafted service maps to show how a networking and referral system might be formalized to better facilitate support needs and progressive project development. In addition to addressing faculty concerns regarding roadblocks to learning about available consultation services, this event sought to better define the role of digital arts and humanities consultants and to examine at what point the consultant (or service center) becomes a partner.

Responding to a desire to learn more about DAH methods, practices, and issues, the working group also partnered with Macalester College's Dewitt Wallace Library to convene Spark Fest: A Twin Cities Digital Humanities Symposium. The symposium had a number of goals:

- Gather scholars from multiple disciplines together to spark transdisciplinary collaboration;

- Serve as an accessible networking and development opportunity for faculty and graduate student scholars, academic technologists, programmers, research consultants, librarians, and other academic support staff from the region; and

- Allow digital arts and humanities scholars and other practitioners to present their work in lightning rounds and learn about a variety of tools through breakout sessions on collaboration, funding, copyright and intellectual property, publishing platforms, coding tools, data visualization, mapping, and digital arts and humanities in the curriculum.

The symposium was well-attended, and participants requested that the symposium be held regularly, with even deeper, hands-on content, training, and logistical discussions.

Events such as the Summit, SparkFest, and the overall investigative work of the group suggested a number of possible next steps toward operationalizing services, but there was still a lack of clarity around the full scope and scale of the digital humanities work on campus. There were also unanswered questions about the resource demands that might emerge when beginning to develop and offer digital humanities services. There are many levels and types of service an organization might offer to foster digital humanities work, and the demands for each project and course appear to be different (Vinopal, 2013, p. 28). In light of the diversity of needs and uncertainty around service adoption, the Libraries embraced a pilot approach to service provision and launched a 2-year phase in summer 2013 to explore methods for operationalizing this work. Taking a pilot approach allows the organization to test the waters and remain nimble and responsive in a period when this research is evolving on the University of Minnesota campus.

In spite of a commitment to being nimble and proactive, there are a number of difficult elements of a pilot period. First, the proof of concept services can appear random and opportunistic, rather than strategic. While opportunity and willing partners are crucial to a successful pilot, diversity in pilot projects also provides a breadth of information about resource demands and builds connections with researchers and instructors with both incipient and well-established interests. Second, concerns about resource demands (staffing, equipment, infrastructure) and sustainability of possible services loom large in the thinking of any organization. There is often unease about pilots setting precedent for user expectations and about the 
ability to support a service portfolio as demand increases. The DAH investigations identified critical gaps in scholar support, and the organization intends to plan for service success. As a result, the University Libraries developed a framework to provide initial definition of "digital humanities" services and to address potential concerns. The framework includes guiding principles and assumptions, acknowledgment of additional strategic planning to be conducted, and a draft service model to describe core areas of work and coalesce pilot activities. The framework also indicates ways that sustainability of services may be addressed based on activities in the pilot phase.

The guiding principles for digital humanities service development at the University of Minnesota Libraries were designed to provide rationale for choices made in the pilot phase of service development, and to address any concerns during a period of ambiguity and change, both from the Libraries internally, and more broadly. The guiding principles are to:

- $\quad$ Seed knowledge on campus;

- Serve as a hub for efforts, not the sole service provider;

- $\quad$ Leverage existing Libraries expertise;

- $\quad$ Pilot to identify sustainable models; and

- $\quad$ Complement existing strategic initiatives.

The discussion below provides examples of how the principles were used to inform choices and shape the development of the service model that would move the Libraries, and potentially the fields of digital arts, sciences, and humanities, forward.

\section{Digital Arts Sciences + Humanities}

The first principle — seeding knowledge on campus — is key to transforming the way digital humanities work is described and advanced on campus, to become included in conversations and initiatives. Achieving this goal necessitated a change in scope from the original working group. The rationale to transition from DAH to Digital Arts Sciences + Humanities (DASH) was born out of reasons both practical and conceptual. It is a practical transition, since the University of Minnesota is not home to a strong, selfidentified digital humanities presence on campus, unlike institutions such as Stanford University, University of Nebraska, the City University of New York, and others who have set up specific institutional centers around digital humanities. A faculty collaborative on digital humanities, organized through Minnesota's Institute for Advanced Study, hosted a number of speakers and conversations around digital humanities; however, this group concluded in 2013. The lack of a departmentally-centered presence that engaged with these ideas and methodologies gave the Libraries a greater amount of freedom to shape the meaning and focus of DASH.

Rather than setting up another division between disciplines, the Libraries opted instead for a more conceptually ecumenical approach, thinking of themselves as a $h u b$. This approach takes advantage of the Libraries' place as a neutral space that interacts with disciplines but also stands beyond any single one. The tools and methodologies most often associated with digital humanities (e.g., mapping, crowdsourcing, data visualization) are utilized in different sectors of campus, including but not limited to the humanities. Examples include work through a well-known crowdsourcing platform (Zooniverse, in collaboration with other institutions around the world), a GIS center (U-Spatial), digital history projects, and the creation of iPad apps in classes. These emerging tools and methods have applicability beyond the humanities, as 
part of a much broader debate about the transformation of scholarship itself. In conversations, including those during the original DAH surveys, many faculty, students, and staff were put off by the term "digital humanities" because they felt it was unduly limiting or did not apply to them since they did not consider themselves in the field of humanities. As a result, when the DAH group put on events, there was very little engagement from scientific disciplines. The inclusion of "sciences" in DASH was key to conveying relevance to such groups as social scientists, computer scientists, biomedical scientists, and agricultural scientists. More broadly this approach allows the Libraries to better understand how individual disciplines use these tools for their own research and pedagogical ends, serve as a low-barrier starting point for people interested in such work, and develop skills amongst library staff to better support them.

\section{Libraries as Hub}

Based on a reputation of outreach and engagement, the University Libraries are beginning to provide a coordinating role for DASH services. As noted above, libraries are a natural hub due to their organizational centrality and status as neutral ground on campus. At the same time, the University Libraries maintain strong connections with other units on campus to avoid duplication of effort and leverage expertise resident elsewhere. Pursuing a distributed service model involves making critical referrals when necessary to provide the most efficient and high quality service possible. Embracing a hub and spoke model of service further fosters the spirit of inclusivity and cross-unit work inherent in DASH and indicated in the principle to seed this work across campus. With DASH, the hub and spoke model operates at both micro and macro levels.

In order for the University Libraries to operate effectively on an institutional level, it has been critical to have an in-house point person for coordinating DASH activities. To that end, the Libraries hired a Digital Humanities Specialist for the organization. The specialist focuses on the outreach efforts necessary to build a community around DASH on campus, promote DASH-related services, pilot service models, and refer to other expertise in the Libraries and on campus as necessary. The role requires significant skills in engagement, teaching, consulting, collaboration, and coordination. Due to the lack of clarity about the level of campus interest in digital humanities in 2012, it was difficult for the University Libraries to dedicate a permanent position to the role at that point in time. As a result, the organization chose an approach that was both cautious and experimental.

The University Libraries chose to hire a postdoctoral fellow for a two-year period through the Council on Library and Information Resources (CLIR) Postdoctoral Fellowship in Academic Libraries program. The program offers recent $\mathrm{PhD}$ graduates the opportunity to explore an alternate academic career in libraries and provides libraries with a fresh perspective on library services and connections to current research practices. In the case of piloting a program to support DASH, a CLIR postdoctoral fellow brings critical knowledge of disciplinary research and teaching practices, recent connections to faculty and graduate students, and enthusiasm for exploring interdisciplinary work. The program helps libraries identify individuals that can serve as "hybrarians" (Watson, 2011, Conclusion section, para. 6) that "occupy the space between the library and the academic departments and serve as digital ambassadors and experimental researchers" (Vandergrift, 2013,p. 71). The two-year window gives a fellow an opportunity to experience academic library culture and determine career fit, and the bounded time frame gives the University Libraries time to explore the depth of campus interest in DASH and extent of service needs, postponing a decision to commit long-term resources. While this can be understandably perceived as "libraries hedging their bets" (Posner, 2013, p. 49), it is a way to address political realities and is also 
an attempt to be nimble and responsive to needs, effectively a personnel pilot. The University Libraries are learning about the deep and diverse interest in digital humanities scholarship on campus and have greater information to support longer-term investment.

One of the roles of the Digital Humanities Specialist is to forge connections within the University Libraries for team support of DASH projects and courses. This includes consulting with and referring to experts throughout the Libraries around data management issues, digital preservation practices, metadata schema, digitization resources, data licensing options, copyright implications in DASH projects, and collection opportunities. Since DASH methods and tools are new to many librarians, the Digital Humanities Specialist also has a role in building that knowledge in the organization and developing staff training to extend the in-house referral network and leverage the University Libraries' robust liaison librarian program. Building library staff knowledge of DASH scholarship, methods, and tools has a number of benefits. For example, it will prepare liaison librarians to discuss this emerging research area with colleagues in academic departments. This builds on existing skills of librarians and is a model emerging at many research libraries (Jaguszewski, 2013). It prepares librarians throughout the organization to assist with bringing DASH tools into courses, to make recommendations for emerging scholarly communication options, and to make effective referrals in support of DASH projects. This professional development will be further addressed in the discussion of sustainability below.

It is critical to note, however, that the expertise to provide DASH services extends well beyond the University Libraries. Another role of the Digital Humanities Specialist is to strengthen partnerships with units on campus to provide support to courses and research projects. This work has been long underway due to the deep and diverse connections on campus built by many members of the University Libraries staff. The Digital Humanities Specialist is helping to identify specific partners that can work together to support new modes of scholarship and teaching. These are partners who are open to piloting services through individual projects and courses. Partners may collaborate on providing project management and project hosting for an undergraduate course exploring DASH methods. Potential partners are also sharing their expertise through workshops and presentations on campus. As an example, training in GIS tools and methods, core to many DASH projects at UMN, is provided by staff of the U-Spatial initiative (referenced earlier). The hope of the University Libraries is that these pilots will evolve into a more robust and affirmed network of support on campus to reduce barriers for scholars seeking to try new methodologies and work in interdisciplinary ways.

\section{Building on Libraries Expertise through Pilots}

The investigations by the Digital Arts and Humanities group indicated that the University Libraries can have a significant impact on fostering DASH scholarship at the University of Minnesota by offering services that build on core areas of expertise in the University Libraries and align with existing services: research consultations, instructional support, and training and development. As a result the draft service model for DASH includes services in the areas of research project consultation, digital pedagogy and instruction, workshops and trainings, and community building.

Piloting different ways to support courses integrating digital humanities methods or consult on research projects provides proof of concept work for an ongoing service. Further, offering different levels of research project support or course support, ranging from consultations to tool development or from a guest lecture to significant project management, provides critical data for gauging resource demands for each service level and organizational capacity for providing that service. The following are examples of pilot work that serve to inform ongoing program development and longer-term service provision. 


\section{Research Project Consultations}

Consultations involve providing education, guidance, and planning advice to actively advance a faculty, student, or staff project. The level of support provided varies depending on the project objectives, potential impact, organizational capacity, and sustainability. In the first year of DASH, the Digital Humanities Specialist (DHS), sometimes alone but often in conjunction with other staff in the Libraries and elsewhere on campus, met with undergraduates, graduate students, and faculty about projects that included Twitter archiving and analysis, social network analysis and visualization through programs like Gephi, multimodal publication creation via platforms like Omeka and Scalar, mapping projects (ranging from Google Maps to ArcGIS), assisting with workflows for large-scale digital storytelling projects, and designing research workflows for digital archival work (including tagging and OCR of digitized archival documents). The majority of this work was initiated through conversations at various events and presentations (described below) where individuals told the DHS or other Libraries staff of an interest in a specific tool or methodology or, conversely, a project they had in mind for which a staff member suggested a specific tool/methodology.

\section{Digital Pedagogy and Instruction}

DASH-related work at the University of Minnesota is a variation of the course and curriculum integration services already offered by liaison librarians, curators, and the Media Outreach and Learning Spaces Librarian. This includes course development, assignment consultations, content awareness, and instruction on research skills, tools, and methods. To date, work related to courses and instructor support for DASH falls into three rough categories. The first consists of the DHS providing one or two workshop-style sessions in a class without much other contact over the course of the semester. An example of this was a Music class that had students utilize mapping for their final project. The DHS gave a basic mapping tutorial, which included examples of digital mapping projects as well as a basic "how-to" of Google maps utilizing Fusion Tables, near the beginning of the semester as a way to get students started with their projects as well as provide them with some inspiration and models. Examples in a second, deeper category of support involve a more sustained presence over the course of the semester, including both presentations and tutorials, but also consultation and assistance in building the individual projects of students in the class. As part of a graduate-level digital history project, the DHS not only showed a number of examples of digital history projects early on in the class, but also helped the three groups in the class conceive of their project from both a conceptual and technical standpoint. Furthermore, the DHS was the main architect for a Scalar publication that was a group's final project. Finally, the third level of support consists not only of a sustained engagement with the students and projects over the course of the term, but an active role in shaping the class itself through consultation with the instructor. A key example of this was another digital history class, this time an undergraduate course, where groups of students created digital projects, including Omeka sites, timelines, Google Sites, and mapping projects utilizing ArcGIS. After working with the faculty member to devise readings and workflows for various aspects of the course, the DHS attended the majority of class sessions, providing a number of class-wide tutorials, individual consultations with groups, back-end technical work in setting up web platforms, and sometimes referring students to other entities on campus with greater expertise. It should be noted that, in keeping with the theme of collaboration both inside and outside the Libraries, the consultations and project development were often done in conjunction with other librarians, staff members in the College of Liberal Arts IT department, and staff in the wider campus IT department. 


\section{Workshops and Trainings}

While considerable training and education is related to specific courses or research consultations, some workshop needs are independent of these contexts. There is demand from faculty, staff, and students on the UMN campus for hands-on training with a variety of DASH tools. This knowledge can be a precursor for experimentation with new methodologies and new research. Over the course of the first year, the DHS offered a number of workshops and training sessions for groups not part of a class. These included multiple orientations for new graduate students (primarily humanities departments); individual workshops on Omeka for interested students, faculty, and staff; a working group on Gephi that included faculty and graduate students; and a research data management workshop for College of Liberal Arts faculty. Some of these were part of existing training opportunities for students and faculty (including data management workshops run by the Libraries as well as an "Education Technology Workshop" organized by campus IT) and provided impetus for further workshops and training opportunities organized by the Libraries and other departments on campus.

\section{Community Building}

Due to the highly collaborative and emergent nature of DASH research, community-building is critical for the initiation of new research, sharing of ideas, and development of new partnerships. The University Libraries have experimented extensively in community building around DASH and the digital tools and methodologies on which DASH focuses.

The DHS organized a monthly "DASHEvent" series focused on specific topics using multiple formats: single presentations, panel discussions, and project showcases. Topics included 3D printing, changing forms of dissertation creation, data visualization, critical code studies, and "DASH in the Classroom," a discussion of various ways digital tools and methodologies are being used by faculty and instructors on campus. Presenters and attendees came from throughout the campus, representing each of the "areas" of DASH (arts, a variety of scientific disciplines, and a number of different humanities departments), and attendance ranged from 20 to 60 . These events are the most tangible manifestation of DASH's vision of an interdisciplinary space built around digital tools and methodologies. Presentations and discussions were recorded and made available for those who could not make the event in person on the DASH website.

As mentioned above, there is very little chance that one college or university will be able to support all of the types of DASH projects utilizing diverse tools (as well as the tools and project types that continue to develop rapidly). This has led the Libraries to invest energy in creating not just an interdisciplinary space through DASH but also an inter-institutional space with other colleges and universities in the region experimenting with DASH scholarship. Like the University of Minnesota, these are schools that lack digital humanities centers, and many do not have a dedicated specialist. The libraries at these institutions are similarly piloting different ways of working with scholars interested in DASH and are building skills and knowledge in their organizations. The University of Minnesota Libraries are partnering with these libraries to share knowledge and build an informal support network. The DHS has traveled to other campuses, including coordinate campuses of the University of Minnesota system (Duluth) and unaffiliated institutions (Macalester College, Carleton College, St. Olaf College) for consulting and networking sessions. The intention is to build upon the pre-existing strengths that these other institutions offer, as well as participate in regional conversations about the best ways to support DH/DASH projects on our respective campuses. In addition, speakers from these other institutions have participated as presenters in University of Minnesota DASH events, through Skype and in person. 


\section{From Digital Arts and Humanities to DASH}

The University of Minnesota Libraries also partnered with these regional institutions to sponsor regional symposia and unconferences, such as DASHCamp, which brought together more than 50 people from across the region, including librarians, faculty, graduate and undergraduate students, and other staff for a day of workshops, discussions, and network building. Topics included data management for digital humanities projects, Scalar, Omeka, timeline-building tools, GitHub, and others. A post-event survey showed respondents all learned something new at the event and overwhelmingly said that they wanted to attend another instantiation of this event. This regional cohort is discovering a large benefit from sharing examples of research, lessons learned, and nascent expertise with tools and methods. These libraries are beginning to draw on the expertise of librarians at regional institutions for consultative advice on best practices, tool training, and workshopping solutions to shared service issues.

\section{Sustainability and Scalability}

Taking a pilot approach to service provision and partnerships has yielded a great deal of information about the types of DASH work conducted on campus and the resource intensiveness of different approaches. However, this fluid approach and tremendous interest in on campus has also made sustainability issues more pressing. Questions about sustainable and scalable approaches to support digital scholarship are endemic among libraries, and the questions do not feel resolved at present (Vinopal, 2013). The University of Minnesota is addressing these sustainability and scalability questions through a few approaches.

Akin to the framework utilized by New York University, and articulated by their Librarian for Digital Scholarship Initiatives Jennifer Vinopal, the DASH Framework incorporates a tier system in the service model to describe varying levels of guidance and partnership (Vinopal, 2013). The framework helped to construct types of potential service, suggest means of support for the service, and briefly describe a decision-making process for each tier of service. A link to the DASH Framework in its entirety can be found in the 'References' section.

Tier 1 services focus on guidance and referrals with minimal resource commitments. Examples of this tier include consultations with a researcher (encompassing one or two meetings) to provide guidance on developing a research project and make referrals to additional campus experts for deeper support; meeting with an instructor to discuss potential methods, tools, and assignment possibilities and providing a single guest lecture or workshop; and providing standalone workshops on core tools and methods, such as Omeka or GEPHI. The information from piloting this service tier is helping us determine the average amount of support. It may be easier to communicate, in the future, that this service tier requires less than 10 staff hours per case. This also assumes the use of common open source tools or enterprise solutions. During this pilot phase, the DHS conducts or coordinates Tier 1 activities and refers to additional experts as needed.

Tiers 2 and 3 are more resource intensive and require greater amounts of staff time. Tier 2 encompasses such activities as developing a course plan with an instructor and teaching several sessions; coordinating open learning communities; planning and facilitating a DASH event series; and doing some basic project development, including back end and front end design. Tier 3 activities are, by necessity, the rarest type of support due to the demands on the organization. These activities include partnering and codeveloping a research project; participating in departmental curriculum development; devoting resources to substantial project and/or tool development; and planning and hosting a large research symposium.

Tier 2 projects are approved through consultation between the DHS and the Arts \& Humanities Department Director as these activities require greater collaboration and resources. Typically, the DHS and 
Department Director will assemble needed experts on an ad hoc basis to support this work. The hope from this approach is that the ad hoc support will allow the organization to "respond flexibly to fast-developing needs" (Vinopal, 2013). However, this also means that time is spent, repeatedly, in assembling ad hoc teams and marshaling support, which is an added challenge (Posner, 2013). Tier 3 activities require approval by Libraries Administration and are reviewed on a case-by-case basis at present. Before the pilot phase, there were few precedents for Tier 2 or 3 DASH projects, so the evaluation and decision-making processes were fluid in order to capitalize on new opportunities. This approach requires a high level of comfort with ambiguity and is only appropriate during a pilot period in an evolving landscape. We have found developing a clear selection process and clarifying decision-making authority to be critical next steps for maturing the DASH program. The pilot phase, however, has been crucial for determining the resource considerations and impact on research, learning, and community building that will inform decision criteria.

The University of Minnesota is addressing sustainability and scalability issues through personnel development. While the DHS has coordinated and conducted much of the operational work during the pilot period, the Libraries have long known that this is not a sustainable model. Principally, the way to make the work of the above pilots sustainable is to have more people involved. The second year of the pilot phase is focused on building staff skills to participate in DASH work and leveraging partner relationships to avoid making the Libraries the sole provider of DASH support on campus. For instance, the Libraries are developing a collaborative training program that will offer a series of separate and multiweek workshops for faculty, students, and staff (including librarians). These are not meant as solely one-off tutorials on a specific tool. Rather, the program is about building cohorts and expanding upon existing skills and knowledge (i.e., adding more skills that a liaison can offer to his or her departments, without necessarily having to refer to the DHS).

Such a program is similar to the University of Maryland Libraries Digital Humanities Incubator, which takes a semester-long approach (Posner, 2013). Many other academic libraries are pursuing this approach to sustainability, including, but not limited to, Columbia University, Indiana University, and the University of Florida. This ethos mirrors the argument presented by Posner (2014) to support "DH people, not DH projects," where training programs build cohorts and distributed knowledge and "remove the pressure to produce something immediately, which so often results in poorly conceived projects." Another goal of this work is to employ a "train the trainer" approach, where the people taking the workshops could integrate it not only into their own work, but also provide support within a specific department, as in a graduate student who receives a teaching assistant or research assistant position solely to support digital projects. Faculty and graduate students could then incorporate these technologies and methods into their classes, without relying completely on the Libraries themselves.

The DASH Framework and service model are works in progress. Instead of four service areas, it may make more sense to combine consultations for research projects and course integration work due to the similarity in skill needs, initial processes, and Tier 1 and 2 time investment. Similarly, there is considerable overlap in the training and community development areas. As indicated above, the Libraries will need to define clear selection criteria for projects in the coming year, and the decision-making processes need attention and refinement. The DASH Framework indicates a need for an advisory group, and it is clearer now what that group should address next.

The training programs underway will boost organizational capacity for DASH work. However, it has become clear through the pilots that the local demand for DASH partnerships is significant and warrants exploring a formal team for Tier 1 and 2 work. Given the benefits of pursuing a distributed model on 
campus and clear interest among students, the composition of such a team is unclear. It could include Libraries staff, academic technology staff, and/or student fellows. Regardless, next steps also include formalizing partnership relationships with other "academic support" and research units on campus to deepen infrastructure commitments.

\section{Assessment}

Data on resource intensiveness and knowledge of capacity will play a key role in determining ongoing service depth, necessary staffing and structures, and effective workflows. The iterative development of a service model is permitting flexible action as the local landscape evolves. Further, it is in keeping with the rapid development cycles and experimental approach inherent in digital humanities work.

In addition to actively looking at the resource intensiveness of pilot work to make decisions about operational models, the Libraries plan to gauge the impact of the emerging DASH program. As indicated in the Value of Academic Libraries report (ACRL, 2010, 11), it is critical to answer the question, "How does the library advance the missions of the institution?" and demonstrate value based on local context. This program assessment is important both for ensuring the investments in DASH are providing desired outcomes and for making the case for Libraries' impact to university administration and the state at large. For instance, as an RU/VH Research University (very high research activity), it is critical to look at programmatic impact on research output. This might be accomplished by capturing case studies from faculty members drawing on DASH research consultation services, discussing the value of the services and Libraries expertise in supporting their project. It is also worth tracking the number of DASH-related projects on campus, the number of grants received for DASH-oriented projects, and reviewing faculty and student publications and conference presentations stemming from this work.

The University of Minnesota is placing increasing emphasis on broad conceptions and practices of eLearning, including technology-enhanced learning, open textbooks, MOOCs, and digital project development. As a result, it is beneficial to capture information on DASH course integration and impact on student learning. This could include gathering feedback from instructors with whom the DHS consulted on course approaches and projects. Assessment would examine the benefits of consultation on initial curriculum design, in-class support, consultation with students outside of class, and the overall effectiveness of the DASH-related student projects in meeting the learning objectives of the instructor. Is there a demonstrable impact on student engagement and critical thinking development? Related to this is the value of integrating DASH methodology knowledge and skill development in graduate education. Feedback from participants in symposia and bootcamp events about the value of the training to expand their strategies for designing and implementing research projects will help to tell the story of impact of the DASH program. Ultimately it would be valuable to examine the impact of the DASH program on humanities PhD placement in academic and alt-academy (alt-ac) positions.

There is a growing emphasis on interdisciplinary research on campus, and DASH exemplifies interdisciplinary research. There are multiple means to demonstrate the dispersion of DASH scholarship and methods across disciplines and to examine the development of interdisciplinary partnerships. It is possible to gather data on the range of disciplines represented at DASH events and seminars. Further, special attention will be paid to note areas where the DASH program played a role in facilitating partnerships between individuals, departments, and colleges. 


\section{CONCLUSION}

The efforts of the Digital Arts and Humanities Working Group laid the foundation for digital humanities support on the University of Minnesota campus. The investigation began with an environmental scan of the field, providing grounding information on digital humanities research and an understanding of the existing best practices for support. The group then turned to a local review of scholarly needs, support options, and research barriers. This was accomplished through a combination of interviews and a survey of local scholars with an expressed interest in digital humanities. This revealed ambivalence about the term "digital humanities" and an expressed difficulty in determining how to begin or pursue this work. There was general consensus that it is difficult to find support for this work on campus, and scholars typically turned to known entities as a starting point for assistance. Interview and survey participants expressed an interest in help with technology, funding, training, and general institutional support. The survey, in particular, revealed a lack of knowledge of preservation practices to ensure the longevity of digital research. The review of campus support infrastructure exposed a broad array of relevant skills and resources, although scholars are typically unaware of the range of services. In part, this is due to the highly distributed and siloed organization of the university. The diffusion of this expertise suggests an opportunity for a distributed service model as a way of providing sustainable support on campus. However, such a model would require substantial coordination.

With the initial investigation complete, the Libraries turned attention to moving from recommending potential services to and beginning to operationalize these services. The group began with intermediate steps to address the areas of greatest need. This included hosting a support summit, bringing together potential service partners on campus. The Libraries also co-developed a networking event, SparkFest, as a venue for discussing local research and advancing regional scholarly conversation on digital humanities.

It is clear that scholars on campus could benefit from expertise resident in the University Libraries in the areas of content and data management, metadata, preservation, and digitization. Similarly, the Libraries offer core consultation services in the areas of research and instruction and regularly offer training in information resources. An expansion of such services to address digital humanities tools and methods could support faculty, staff, and students beginning to delve into this work. Acknowledging the diversity of scholars' needs, the Libraries also began to explore a distributed service model as a feasible means of advancing scholarship on campus, leveraging the Libraries central and discipline-neutral stance on campus. In response, the Libraries hired a DHS to pilot digital humanities services and begin the work of coordinating campus support. At that time the program name also shifted from Digital Arts and Humanities to Digital Arts, Sciences + Humanities (DASH) to better address scholars' concerns about the term "digital humanities" and express disciplinary inclusivity.

The DHS has been able to pilot services in the areas of research consultation, instructional consultation, training programs, and community building. The pilots have provided information on the resourceintensiveness of these services, uncovering both what is sustainable and what is not. The work of the DHS has also confirmed and further uncovered the extent of interest on the University of Minnesota campus in DASH work. Work with graduate students and embedding DASH methods and tools in the classroom has been particularly fruitful. This pilot work has provided rationale for deeper investment in the DASH program.

As evidenced by the growing interest in workshops, course support, and regional networking, the University of Minnesota Libraries appear to be in a position of needing to plan for success. The initial investigations and ongoing pilots are providing the information needed to make this expansion smooth and help define the ongoing value of the University of Minnesota Libraries in providing access, support, and encouragement as pedagogical and research methodologies continue to evolve. 


\section{REFERENCES}

Alvarado, R. (2011). The Digital Humanities situation. The Transducer. Retrieved from http://transducer. ontoligent.com/?p=717

Association of College and Research Libraries. (2010). Value of academic libraries: A comprehensive research review and report. Chicago, IL: Association of College and Research Libraries. Retrieved from http://www.ala.org/acrl/sites/ala.org.acrl/files/content/issues/value/val_report.pdf

Bryson, T., Varner, S., Pierre, A. S., \& Posner, M. (2011). SPEC Kit 326, Digital Humanities. Association of Research Libraries. Retrieved from http://publications.arl.org/Digital-Humanities-SPEC-Kit-326/

Fitzpatrick, K. (2011). The Humanities, done digitally. The Chronicles of Higher Education. Retrieved from: http://chronicle.com/article/The-Humanities-Done-Digitally/127382/

Jaguszewski, J., \& Williams, K. (2013). New roles for new times: Transforming liaison roles in research libraries. Washington, DC: Association of ResearchLibraries; Retrieved from http://www.arl.org/storage/ documents/publications/NRNT-Liaison-Roles-final.pdf

Lach, P. (2012). Digital Innovation Lab to be involved in new Carolina Digital Humanities Initiative. Retrieved from http://digitalinnovation.unc.edu/2012/07/06/digital-innovation-lab-to-be-involved-innew-carolina-digital-humanities-initiative/

Liu, A. (2012). The state of the Digital Humanities: A report and a critique. Arts and Humanities in Higher Education, 11(1-2), 8-41. doi:10.1177/1474022211427364

McPherson, T. (2009). Introduction: Media studies and the Digital Humanities. Cinema Journal, 48(2), 119-123. http://muse.jhu.edu/login?auth=0\&type=summary\&url=/journals/cinema_journal/ v048/48.2.mcpherson.pdf doi:10.1353/cj.0.0077

Posner, M. (2013). No half measures: Overcoming common challenges to doing Digital Humanities in the library. Journal of Library Administration, 53(1), 43-52. doi:10.1080/01930826.2013.756694

Posner, M. (2014, March 18). Commit to DH people, not DH projects. Retrieved from http://miriamposner.com/blog/commit-to-dh-people-not-dh-projects/

University of Minnesota Digital Arts \& Humanities Working Group. (2012). Digital Arts and Humanities Working Group 2011-2012 Report. Minneapolis, MN: University of Minnesota Libraries. http:// hdl.handle.net/11299/36776

University of Minnesota Libraries. (2013). Digital Arts Sciences + Humanities (DASH) Framework. Minneapolis, MN: University of Minnesota Libraries. http://hdl.handle.net/11299/163067

Vandegrift, M., \& Varner, S. (2013). Evolving in common: Creating mutually supportive relationships between libraries and the Digital Humanities. Journal of Library Administration, 53(1), 67-78. doi:10 $.1080 / 01930826.2013 .756699$

Vinopal, J., \& McCormick, M. (2013). Supporting digital scholarship in research libraries: Scalability and sustainability. Journal of Library Administration, 53(1), 27-42. doi:10.1080/01930826.2013.756689 
Watson, A., Hswe, P., French, A., \& Williford, C. (2011). Of hybrarians, scholar-librarians, academic refugees, \& feral professionals. Retrieved from http://mediacommons.futureofthebook.org/alt-ac/pieces/ hybrarians-scholar-librarians-academic-refugees-feral-professionals

Zorich, D. M. (2008). A survey of Digital Humanities centers in the United States. Washington, DC: Council on Library and Information Resources.

\section{KEY TERMS AND DEFINITIONS}

DASH: An acronym of "Digital Arts Sciences + Humanities," DASH is a cross-disciplinary initiative organized around emerging digital tools and methodologies for scholarly, pedagogical, and artistic projects.

Infrastructure: Fixed resources needed for the support of program, including personnel, technology, and defined services.

Iterative Approach: Improving a program or process through repetition and incremental improvements.

Multimodal Scholarship: The use of multiple digital mediums, sources, and platforms to communicate research.

Operationalize: The process of moving from a pilot or test phase to a permanent and core service, as indicated by fixed resources, confirmed staffing, and defined services.

Pilot Phase: A period of trial and experimentation to demonstrate proof of concept.

Sustainability: The ability of a service or product to continue indefinitely with planned resources. 


\section{APPENDIX}

\section{In-Person Interview Questions}

1. Do you consider yourself to be a digital humanist? [If the answer is "no" ask: Are you hoping to work in this area in the future?]

2. What are you working on?

3. What are the challenges of digital [arts and] humanities scholarship, [or with working with or creating digital content]? What's difficult?

4. If you need help with digital [arts and] humanities scholarship, what kind of support do you need and where do you find it? Is it available here [at the University]?

5. Do you work with others on these projects? [If so, who are your main collaborators--here at the U or at other institutions?]

6. Has your department been involved with your initiatives? If so, how has the department been supportive or collaborative?

7. Has your department been involved in any Digital arts or humanities initiatives? If so, how has the department been supportive or collaborative?

8. If your work produces new material--new digital collections, new data, new information beyond a scholarly publication-what happens to it? Where does the raw material end up? How do you manage it?

9. What role does digital art or humanities content/digital scholarship have in your teaching?

10. Who is the audience for your digital [art and] humanities research?

\section{Online Survey Questions}

1. Do you consider yourself a digital humanities scholar?

2. What digital arts and humanities project are you working on? Or planning?

3. What are the challenges of digital humanities or digital arts scholarship? Answer all that apply.

4. If you need help with digital humanities or digital arts scholarship, what kind of support do you need? Answer all that apply.

5. Where do you seek and/or receive support?

6. Do you work with others on these projects? If so, who are your main collaborators-either here at the $\mathrm{U}$ or at other institutions?

7. Has your department been involved in any digital arts or digital humanities initiatives? If so, how has the department been supportive or collaborative?

8. Have you incorporated digital arts or digital humanities or digital scholarship into your teaching? Check all that apply.

9. If your work produces new material--new digital collections, new data, new information beyond a scholarly publication-what happens to it? Where does the raw material end up? How do you manage it?

10. Who is the audience for your digital art or digital humanities research? Check all that apply.

11. Are you hoping to work in this area in the future? Check all that apply:

12. May we contact you for a follow up interview? 